\title{
A New Quality Monitoring System for Friction Stir Welded Joints of Aluminium Pipes
}

\author{
Ibrahim Sabry ${ }^{1}$, and A. M. El-Kassas ${ }^{2}$ \\ ${ }^{1}$ Production Eng., Modern Academy for Engineering and Technology, Egypt \\ ${ }^{2}$ Production Eng., Faculty of Eng., Tanta University, Egypt
}

\begin{abstract}
Friction stir welding (FSW) of pipes is tedious due to complex geometry, and hence, research articles related to it are rare. Pipes have face defects will exhibit lower strength joints produced by FSW method. A reduction of $50 \%$ in strength is resulted due to the presence of a notch on the before-welded surface of the pipe. This issue can only be tested by different destructive/non-destructive tests after process not during. These tests come with additional costs to verify that the joint is free of these defects' results. This paper proposes a new approach for controlling face defects behaviour during FSW process, not after. This approach depends on monitoring the measured current of machines used for FSW process. The efficiency of the approach was proved using visual inspection, hardness and tensile test for FSW welded joints. The ampere (current) consumption varied significantly in each of FSW stages clearly distinguishing the tool penetration, dwell time, traverse tool movement and tool pull out. The experimentation was successful in laying the foundation for the ampere consumption signifying the importance of weld quality.
\end{abstract}

\section{Introduction}

The demand for the instant monitoring of weld quality irrespective of the welding techniques has fostered researchers to develop novel methodologies based on potential sources. Friction stir welding (FSW), being a solidstate welding process, results in less deformation in the workpiece. The lower heat input of the friction stir welding process provides an added advantage of producing welded joint with less distortion. The absence of the porosity, spatter, fumes and no requirement of filler wire and shielding gas are the merits of FSW compared to arc welding processes. The superior ability of FSW for welding dissimilar and low melting point metals have revolutionized the welding industry enabling the process to opt for applications involving thin metals [1,2]. Each of the welding processes is a stochastic process in which the quality depends on several factors. The optimum welding parameters are required for high strength and leak proof joint. The travel speed, rotational speed, tool tilt angle, plunge depth, dwell time, tool geometry, plunge speed, axial force are the major parameters in FSW. The penetration of the pin and the shoulder on the workpiece exerts welding forces along three directions - vertical force, traverse and lateral force. These forces along with rotational speed and traverse speed are the primary sources for generating the frictional heat energy in the friction stir welding process. As heat produced in the joint cause's metallurgical transformations [3], it is vital to select the parameters precisely for attaining quality welds.

The temperature generated, and cooling rate have a strong correlation with the distortion defect and the weld quality. The temperature is asymmetrically distributed along the advancing and retreating side in the friction stir welding process [4]. The advancing side temperature is vaguely higher than at the retreating side in the friction stir welding of the aluminum alloys [5]. The plunging force, temperature, torque are powerful potential sources of information regarding the weld quality. The quality inspection of the product is inevitable in the manufacturing industry. The past researches in the development of alternative methodologies for inspecting the friction stir welded samples indicated the significance of relying on these potential sources. The easiness for determining the weld behavior, pre-setting the parameters and an immediate indication of abnormal conditions affecting the quality of the weld are the exceptional advantages compared to conventional non-destructive tests. With the aid of $\mathrm{K}$ type thermocouples arranged along the weld line and at a specific distance away from the weld line, it was proved that the peak temperature at the nugget and heat affected zones has a high correlation with strength, ductility and precipitate characteristics such as shape, size, and distribution. Temperatures at different weld zones are proved to be useful for monitoring the weld quality in the friction stir welding process [6]. 
The dynamometers are used extensively for measuring the forces. The friction stir welding relies on the frictional force generated between the friction stir welding tool and the workpiece. In fact, the plunge depth and tool force are critical parameters. Due to the immense capability of multi-axial sensors to sense the forces acting along three axis, it has been equipped in the friction stir welding machines to capture the friction welding tool force on the welded coupons. The welding force along the tool axis and travel direction obtained from dynamometer was found to differ according to variant pin axis and shapes [7]. The shape of the pin in the tool or the tool shape has a predominant influence on the force and the material flow [8]. The friction stir welding has main four stages - tool plunging, dwell stage, welding stage and tool pull out stage. The vertical forces ought to vary in these four stages. The process parameters influence the vertical force and temperature in a friction stir welding process. The mechanical properties of magnesium alloys such as ultimate strength and elongation have higher values at the lower vertical force and highest temperature in the friction stir welding process [9]. The force and torque measurements in friction stir welding of composite indicated that the material in contact with the shoulder affects the material flow [10]. Many force measuring sensors are developed after designing for weld quality evaluation $[11,12]$. New indirect techniques without using traditional dynamometer and load cells are proposed for the simultaneous assessment of force and torque [13]. The force and torque data undergo abrupt changes during the formation of the defect. The statistical evaluation such as discrete wavelet analysis of these signals is used for identifying the defect and defect-free welds $[14,15]$.

The texture of the friction stirs weld image, acoustic signals produced while welding, current values are also effectively used apart from the force, torque, and temperature for the weld quality inspection. The digital image processing techniques can be used for classifying the surface defects such as cracks, voids, grooves, flash and keyhole confined to friction stir welding [16]. The histogram of the grayscale intensified weld image plotted using the intensities differs when the pin fails, and at different plunger depths [17]. The acoustic signals are an excellent source, when effectively used, can categorize the weld quality [18]. The wavelet transform analysis of the captured sound signal during the FSW process can detect the common gap defects [19]. The statistical evaluation of the spindle motor current captured using Hall effect transducer can be used for predicting the ultimate strength of the weld [20]. The data mining algorithms have phenomenal ability to train the data and to test the predicting variable. The current and voltage signals from the power source can locate the porosity using a control chart and probability density distribution in gas metal arc welding [21]. The majority of the discussed techniques works properly irrespective of the welding techniques. Investigation of the potential sources has been a crucial factor in enhancing the capability of welding and inspection. Therefore, the wide scope and the potential capability of the ampere (current) in evaluating the quality of the weld are explored in the current research. Prime importance is given to investigate the effect of the ampere (current) in obtaining welding efficiency. Moreover, the research focusses on the friction stir welding of $\mathrm{Al}$ 6063pipes.

\section{Materials and Methods}

The friction stir welding was performed on $\mathrm{Al} 6063$ pipe. The pipe has a diameter of $30 \mathrm{~mm}$ and a thickness of 2 $\mathrm{mm}$. The composition of the $\mathrm{Al} 6063$ is given in Table 1.

Table (1) Chemical composition (wt. \%) of Al 6063

\begin{tabular}{|l|l|l|l|l|l|l|l|l|l|}
\hline Weight $\%$ & $\mathrm{Al}$ & $\mathrm{Si}$ & $\mathrm{Fe}$ & $\mathrm{Cu}$ & $\mathrm{Mn}$ & $\mathrm{Mg}$ & $\mathrm{Cr}$ & $\mathrm{Zn}$ & $\mathrm{Ti}$ \\
\hline 6063 & $\mathrm{Bal}$ & 0.2 & 0.3 & 0.1 & 0.4 & 0.9 & 0.04 & 0.1 & 0.12 \\
\hline
\end{tabular}

The ultimate strength of Al 6063 and the Vickers hardness were $406 \mathrm{MPa}$ and $110 \mathrm{HV}$ respectively. The results of tensile and Vickers hardness tests conducted to determine the mechanical properties of the investigated Al 6063 were close to literature values [22-24]. The pipes are mounted in a developed fixture rigidly. During the welding process, the tool is pierced with certain penetration depth. The pipes were welded using friction stir welding equipment Egypt (EG)FSW. The spindle current consumed for the welding process is acquired for every weld. The schematic diagram showing the overall friction stir welding process is shown in Figure 1, and the schematic flowchart of the experimentation is shown in Figure 2. Also, the real welding setup for the experimentation is shown in Figure 3. 


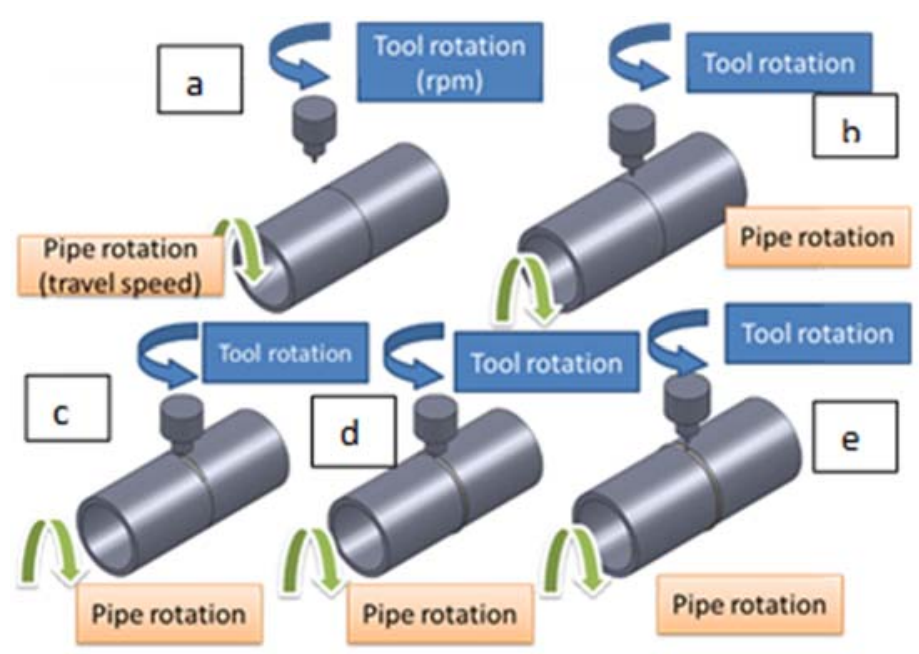

Figure 1 Representative diagram of the friction stir welding of pipes. a) Tool and pipes are mounted in FSW machine. b) FSW tool penetrates to a determined penetration depth. c) Tool rotates with fixed rotational speed, and the pipes rotate at a fixed travel speed. d) Machine travels tool through and along Joint.e) The tool is pulled back after the completion of the FSW process.

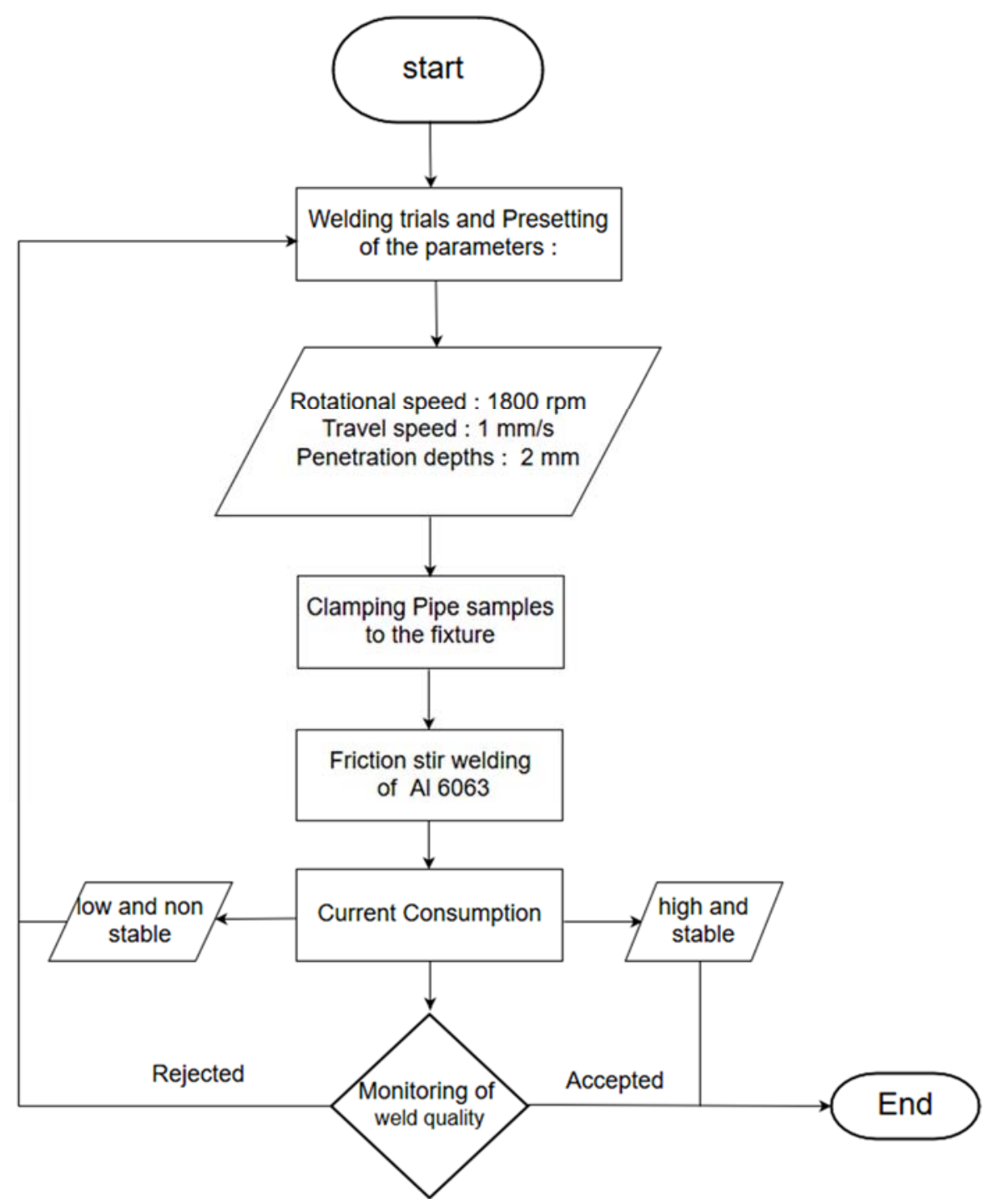

Figure 2 Experimentation flowchart of the FSW with sensors 


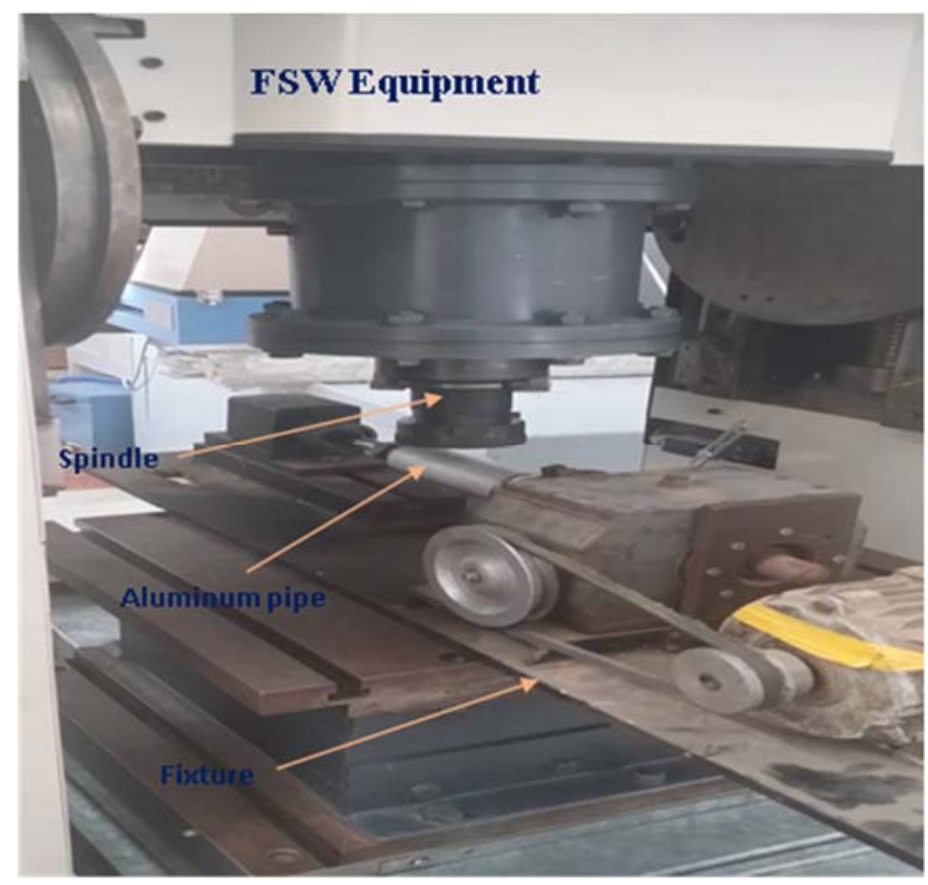

Figure 3 FSW of AL 6063 pipes using EG-FSW equipment

The rotational speed and feed rate were fixed at $1800 \mathrm{rpm}$ and $1 \mathrm{~mm} / \mathrm{s}$ respectively after several welding trials. Ppenetration depths investigated were $2 \mathrm{~mm}$. The tool tilt was kept constant at $2^{\circ}$. The geometrical dimensions of the conical friction stir welding tool that is used for the experimentation are shown in Figure 4, and the parameters used for the welding of Al 6063 pipe are listed in Table 2.
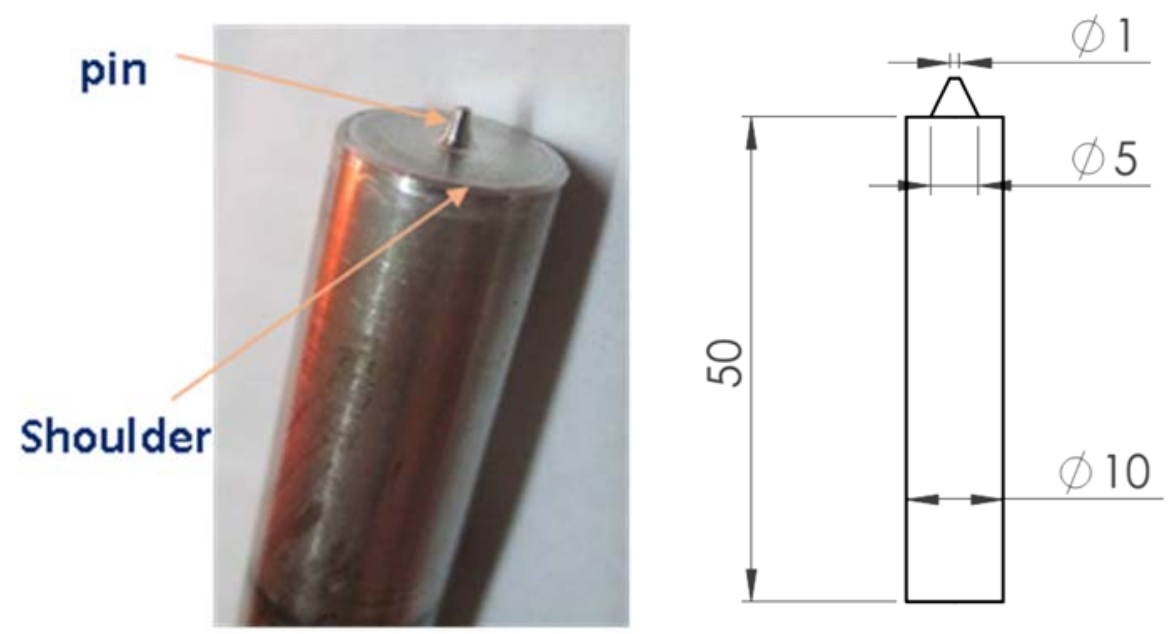

Figure 4 Friction stir welding tool with a conical pin profile (a) Photo FSW tool and (b) Tool dimensions.

Table 2 Parameters for friction stir welding of Al 6063

\begin{tabular}{ll}
\hline Parameter & Value \\
\hline Tool rotation $[\mathrm{rpm}]$ & 1800 \\
Tool feed rate $[\mathrm{mm} / \mathrm{s}]$ & 1 \\
Tool tilt angle & $2^{\circ}$ \\
Tool plunge $[\mathrm{mm}]$ & 2 \\
Tool shoulder diameter $[\mathrm{mm}]$ & 10 \\
Shoulder height $[\mathrm{mm}]$ & 50 \\
Pin minor diameter $[\mathrm{mm}]$ & 1 \\
Pin major diameter $[\mathrm{mm}]$ & 5 \\
\hline
\end{tabular}




\section{Results and Discussion}

The optical micrograph of Al 6063 is shown in Figure 5. The grains are coarse and are oriented along the direction of the extrusion process. The dark spots indicated the evidence for the presence of fine particles of precipitated $\mathrm{Mg} 2 \mathrm{Si}$ eutectic that are evenly distributed in the parent material. I.e., the precipitated alpha grain particles are distributed in an elongated script-like structure with fine spheroids [25].

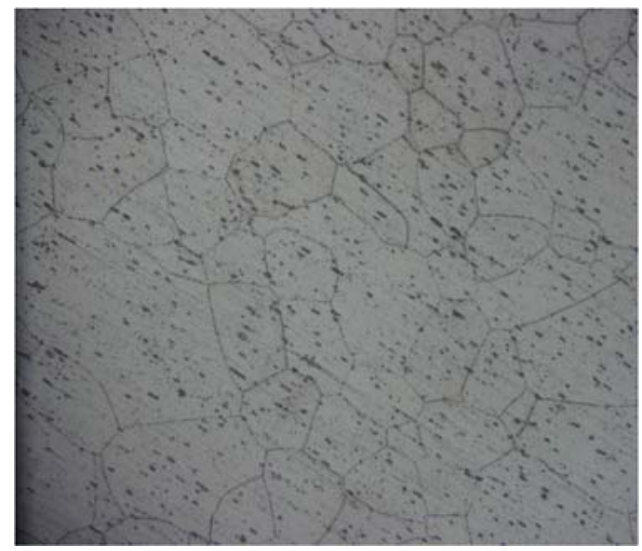

Figure 5 Micrograph of Al $6063(200 \mu \mathrm{m})$

Figure 6 shows the macroscopic cross-sections of the friction stir welds at different penetrations $2 \mathrm{~mm}$. The nugget zone (NZ) is dynamically recrystallized (recrystallization due to deformation) because of the force exerted by the FSW tool and the heat generated due to friction. Since the nugget or dynamically recrystallized zone was directly exposed to thermo-mechanical processing, fine and equiaxed grains are formed at the nugget zones. These fine grains are formed due to excessive plastic deformation and dynamic recrystallization. Nonevidence for the tunnel and kissing bond defect indicated the quality of the weld produced.
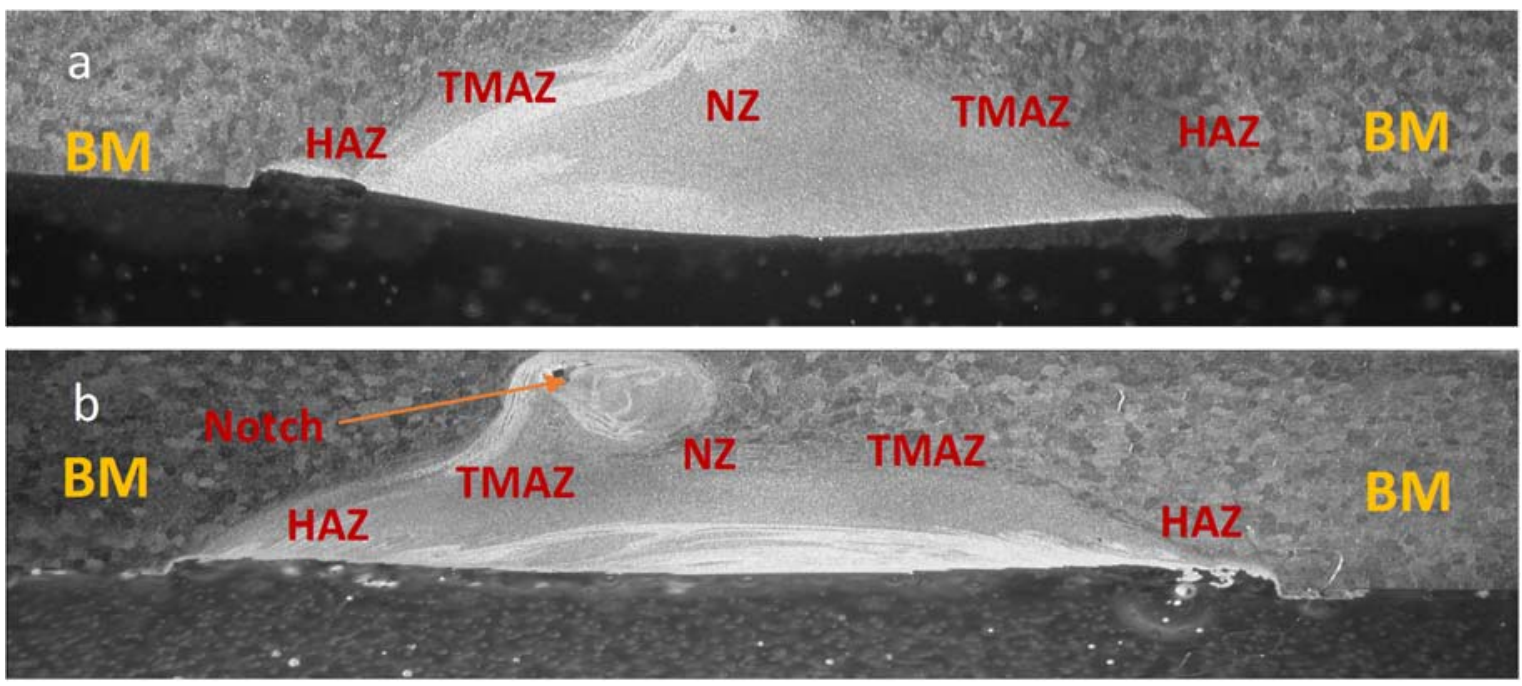

Figure 6 Weld cross-section macrograph of Al 6063 (a) without notch (b)with notch.

The microscopic images of the weld at 2 different FSW without notch and with notch are presented in Figure 7. The three regions - base metal (BM), heat affected zone (HAZ) and thermomechanical heat affected zone (TMAZ) and their separations are clearly visible. The inter-metallic particles are dispersed in the HAZ region causing the grains to be slightly coarser than that of the NZ and TMAZ. The recrystallized TMAZ contained fine dispersed spheroids with more precipitates compared to the parent material. The microstructure on the nugget zones has nonuniform bands (dark and light) that were found due to the distribution of elements causing different chemical compositions in different regions. The dark band is due to the localized higher concentration of $\mathrm{Mg}, \mathrm{Si}, \mathrm{Mn}$ and Fe. These regions of their higher concentrations are found to exhibit more hardness compared to other regions [23]. 

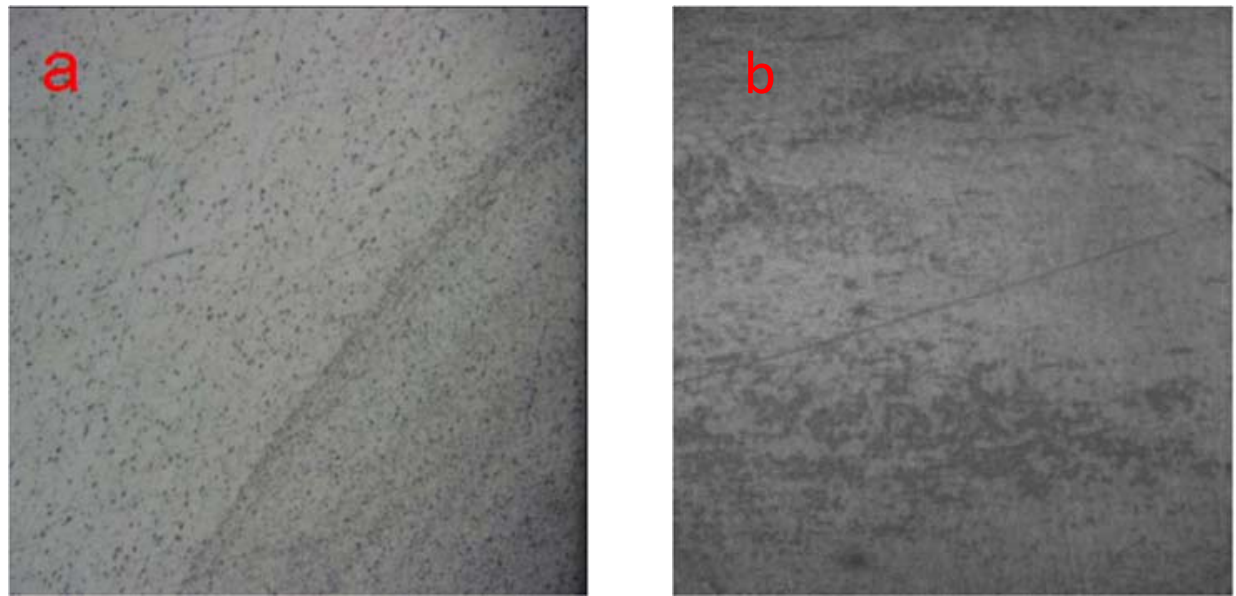

Figure 7 Optical microscopic images of the weld at $200 \mu \mathrm{m}$ magnification (a) without notch (b) notch

As observed earlier, the thermo-mechanical processing caused the refinement of the grains. These changes in the size and shape of the grains are supposed to alter the mechanical properties of friction stir welded Al 6063. Therefore, the Vickers hardness along the transverse direction across the weld was measured and plotted as depicted in Figure 8. The hardness at the nugget zone (avg.85 HV) is slightly lower than that of the parent material (avg.110 HV). This is because of the dissolution of the participates during the stirring action [23]. The micro Vickers hardness along the transverse cross-section of the weld is of the order: BM $>$ NZ $>$ TMAZ $>$ HAZ. It was found that the hardness in the advancing side is comparatively lower than that of the retreating side in HAZ region (i.e., $40 \mathrm{HV}$ and $58 \mathrm{HV}$ in the advancing and retreating side respectively). Therefore, the advancing side is found to be slightly softened region compared to that of the retreating side.

This phenomenon is due to the coarsening of the precipitate because of frictional heat. Holding the weld region for a long time above the solvus temperature can also result in softening due to coarsening of the precipitates. Moreover, the high heat input on the advancing side because of high-velocity difference between the FSW tool and parent material compared to retreating side caused the widening of the softer region in the advancing side. A considerable rise in the hardness from HAZ to BM is observed from $9 \mathrm{~mm}$ and $8 \mathrm{~mm}$ away from the weld center for the advancing and the retreating side respectively. This indicated the influence of thermo-mechanical processing on the metallurgical transformation.

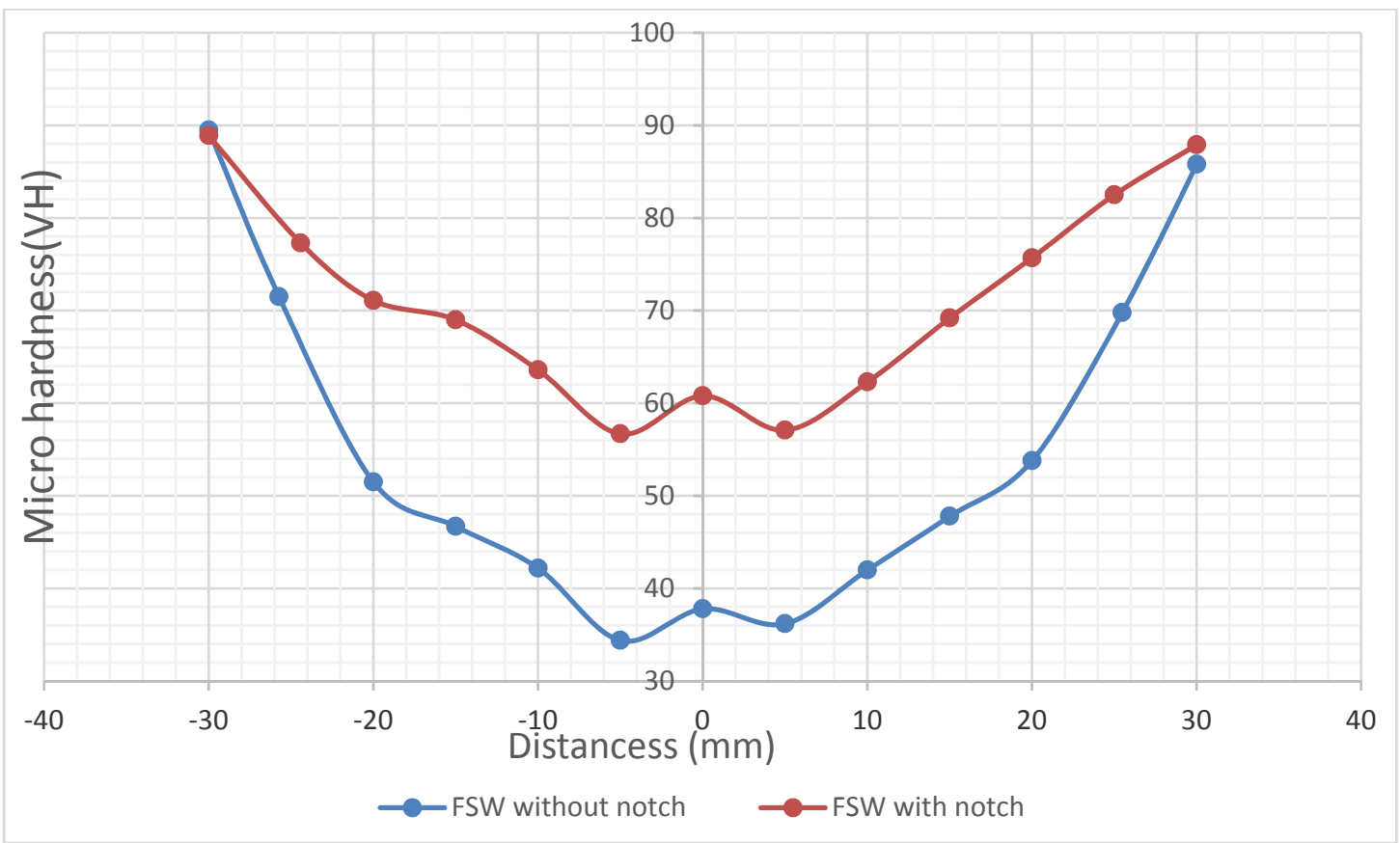

Figure 8 Vickers hardness at FSW without notch and FSW with notch 
Representative friction stirs welds of the Al 6063 pipes using without notch and notch at fixed rotational speed $(1800 \mathrm{rpm})$ and travel speed $(1 \mathrm{~mm} / \mathrm{s})$ are shown in Figure 9 . The penetration depth of the shoulder was found earlier to have a significant effect on the characterization of the material flow especially in the friction stir zone [26]. The distinguishable leading edge (advancing side) and the trailing edge (retreating side) with shoulder marks were clearly visible on the nugget zone in the case of the weld with a notch (Figure 9 (a)). The formation of the shoulder marks is inappropriate in the friction stir welding process. It is noted from visual inspection that the shoulder mark has caused

the joint to be very rough. Their presence indicates the need for optimizing the welding parameters. Therefore, it can be concluded that the notch is not suitable for this case. The fact, the lower penetration depth of the shoulder has an increasing chance of imparting the occurrence of tunnel defects [27,28], recommends avoiding lower penetration depths. At a higher penetration depth, i.e., at $2 \mathrm{~mm}$ (without notch), the surface is smooth with fewer shoulder marks. More frictional heat generated because of greater tool to workpiece interaction might have provided enough heat energy for adequate bonding
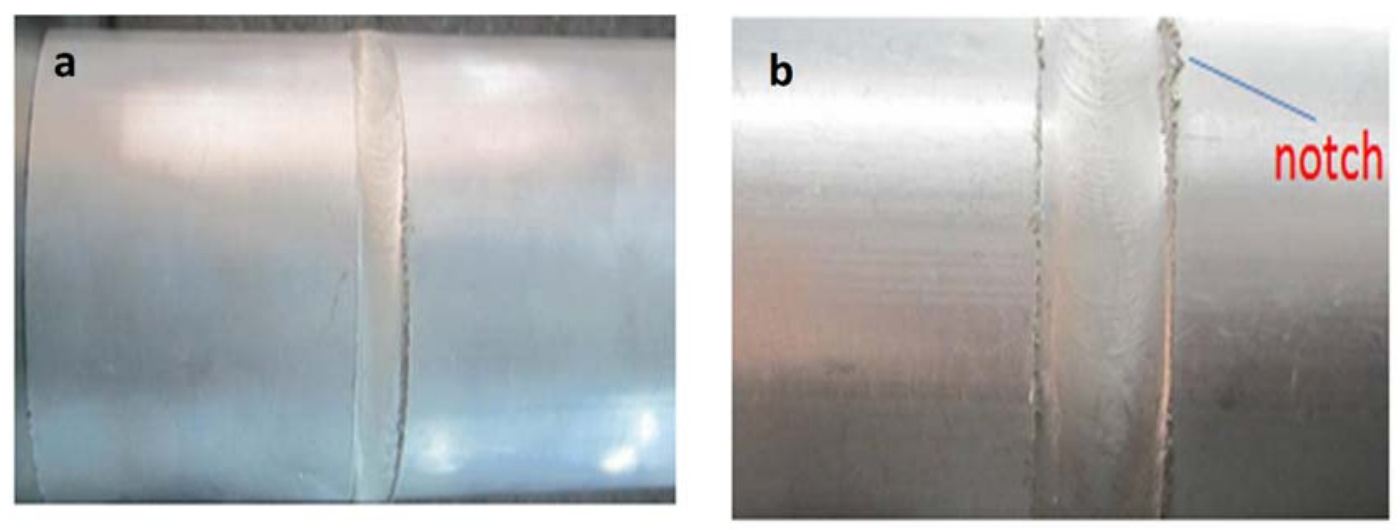

Figure 9 Friction stir weld images of Al 6063 pipe (a)without notch (b)with notch

The result of the tensile tests that were conducted for determining the strength of the $\mathrm{Al} 6063$ welded samples is provided in Figure 10. The ultimate tensile strength of the welds at notch and without notch - are $228 \mathrm{MPa}$ and $350 \mathrm{MPa}$ respectively, whereas that of base material is $406 \mathrm{MPa}$. Within the investigated range of penetration depths, a behavior of the rise in the strength with the penetration depths is noted. I.e., the higher the penetration depth, higher is the tensile strength and vice versa. The percentage reduction of the strength for those welds with notch and without are $13.79 \%$ and $17.73 \%$ respectively compared to that of a base material,

which is acceptable. But, $50 \%$ reduction in strength, when the pipes were welded using notch, is unacceptable as it reduces the load bearing capacity considerably. More volume of tool-to-workpiece interaction and friction creating subsequent material flow and optimal heat generation because of high penetration depth is the reason for producing high strength welds [29]. Henceforth, from the tensile test results, it can be deduced that the weld corresponding to without $\mathrm{mm}$ is quality weld. Henceforth, the distribution of the stress and strain indicated the significant effect of the penetration depth as a parameter on the tensile strength. As strength was altered with different penetration depths, it is confirmed that the extent of the tool to workpiece interaction has an influence on the mechanical properties. This recommends the need for an optimized condition for the enhanced properties of the joint. 


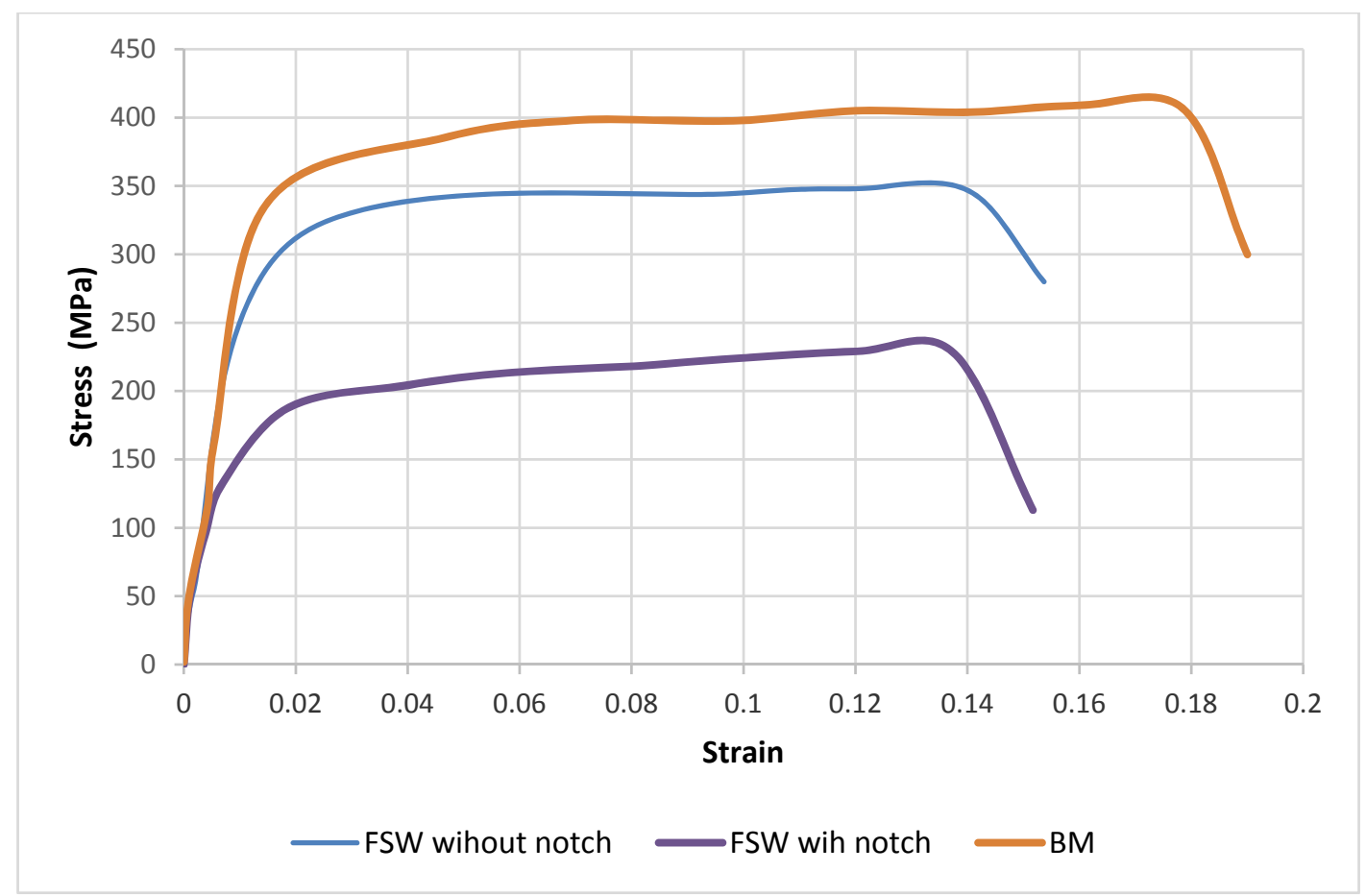

Figure 10 Stress-strain curve of welded Al 6063 samples from tensile test for notch and without notch

Figure 11 shows the captured current plotted over time for the friction stir weld at two different FSW with notch and FSW without notch. It was earlier proved that the spindle motor current signal is a potential source for monitoring the FSW process and the quality [33-36]. From the graphs, the various stages involved in FSW such as tool penetration, traverse movement, dwell time and tool pull out are distinguishable. It is evident from the observation that the current distribution followed a unique trend in each of the stages and the curves are repeatable. In this case, the distribution of the current over time is overlapping for the welds performed at different FSW with notch and FSW without notch. This indicates the insensitivity of the current to the parameter - FSW without notch. But, there is an unusual variation in the current at the start and end of the tool traverse motion for the weld with FSW with a notch. It is suspected to have an impact on the weld quality as it produced a rough weld joint with shoulder marks. The current flow at no load condition was 6.4 A.

The current consumption gradually increased to a peak value of 9.8 A during the plunging action. During the dwell time, the tool was kept penetrated in the starting location for some time causing the softening of the material. Hence the current dropped to 8.1 A and was maintained throughout the traverse motion of the tool. The current consumption gradually decreased to a low value of 6.4 A during duo to notch in samples pipe at FSW process with notch.

During the dwell time, the tool was kept penetrated in the starting location for some time causing the softening of the material. Hence the current dropped to $8.1 \mathrm{~A}$ and was maintained throughout the traverse motion of the tool. After finishing the friction stir welding process, the current dropped to $1 \mathrm{~A}$ when the tool was pulled out from the workpiece. It is clear from the study that the current is sensitive to the different stages of the friction stir welding process. But, the current (ampere) consumption influences welding quilt at FSW with notch or FSW without notch of $\mathrm{Al} 6063$ at constant spindle speed. 


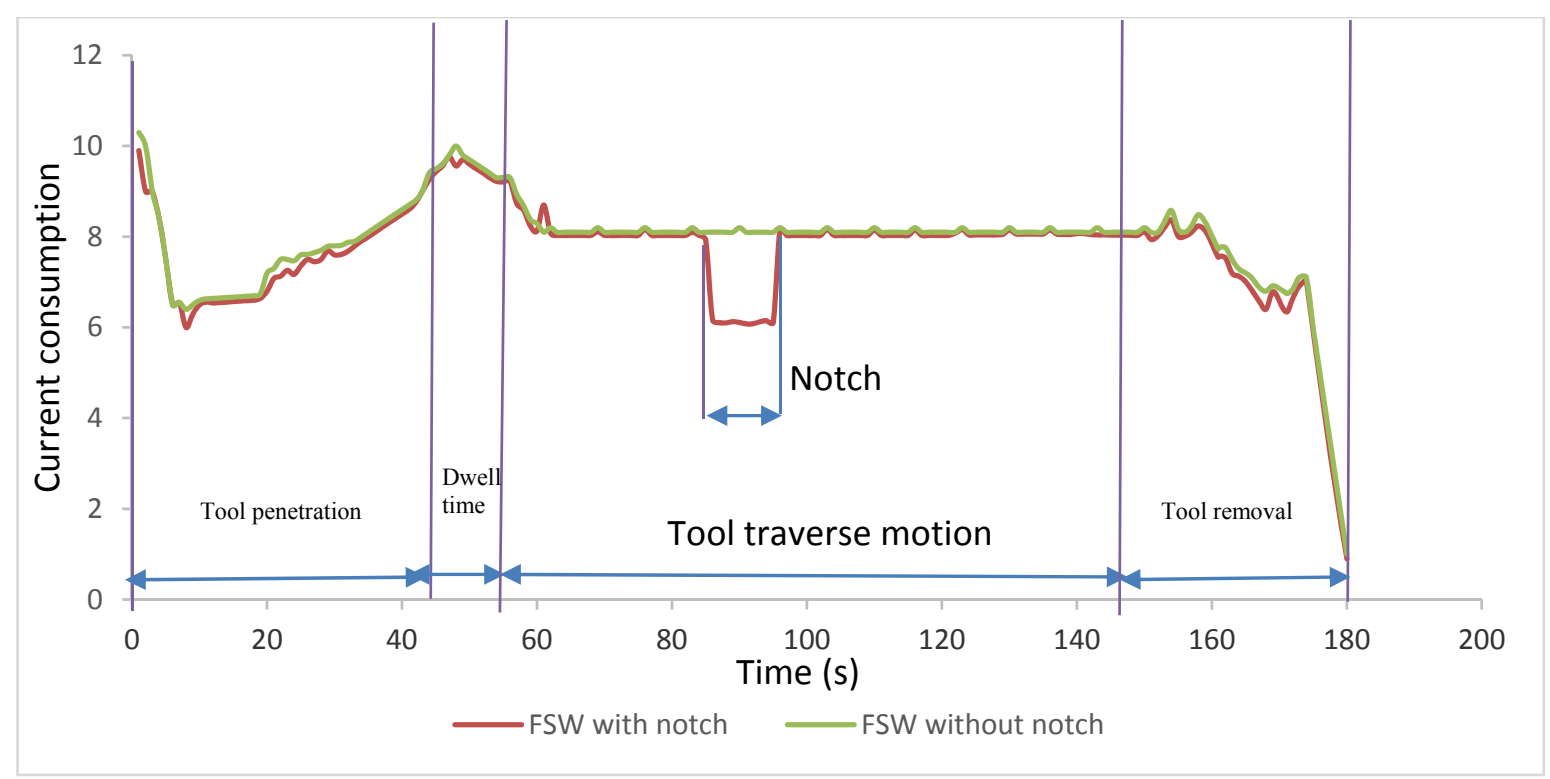

Figure 11 Current consumption during friction stir welding of Al 6063 pipes (a) without notch (b)with notch

It was evident from research that the quality of the weld depends on several factors in which the forces and moment exerted by the tool are predominant. The FSW without notch and FSW with a notch in pipe specimens were not used monitoring the welding quality suitably for Al 6063 pipe specimens within the experimented pipe dimensions. the strength of the joint having partially with FSW notch welds will be less compared to completely FSW without notch welds. To ensure the in double-sided welding is possible to test internal side the circular crosssection of the pipes. Firmly, current (ampere) consumption has a significant role in producing quality welds and should be considered as an NDT in FSW test.

\section{Conclusion}

Based on experimental investigation microstructure and mathematical model carried out on welded pipe of aluminium Al 6063 prepared according to FSW processes, the following conclusions are given:

1. The strength for the welds at FSW with notch and FSW without notch - is $228 \mathrm{MPa}$, and $350 \mathrm{MPa}$ respectively whereas that of parent material is $406 \mathrm{MPa}$. In this case.

2. The current (ampere) increased from $8 \mathrm{~A}$ at FSW without a notch in a pipe and $6.1 \mathrm{~A}$ when the FSW with a notch in a pipe decreased.

3. The various stages involved in FSW such as tool penetration, traverse movement, dwell time and tool pull out are distinguishable from real-time current data.

4. Given the importance to the inspect weld quality of friction stir welded pipe ratio to the current consumption, traverse movement, dwell time and tool pull out are distinguishable from real-time current data.

\section{REFERENCE}

[1] S. Ahmed, P. Saha, Development and testing of fixtures for friction stir welding of thin aluminum sheets, J. Mater. Process. Technol. 252 (2018) 242-248.doi:10.1016/j.jmatprotec.2017.09.034.

[2] T. Mira-Aguiar, D. Verdera, C. Leitão, D.M. Rodrigues, Tool assisted friction welding: A FSW related technique for the linear lap welding of very thin steel plates, J. Mater. Process. Technol. 238 (2016) 73-80. doi: 10.1016/j.jmatprotec.2016.07.006.

[3] A.H.I. Mourad, A. Khourshid, T. Sharef, Gas tungsten arc and laser beam welding processes effects on duplex stainless steel 2205 properties, Mater. Sci. Eng. A. 549 (2012) 105-113. doi:10.1016/j.msea.2012.04.012.

[4] M. Maeda, H. Liu, H. Fujii, T. Shibayanagi, Temperature Field in the Vicinity of FSWTool During Friction Stir Welding of Aluminium Alloys, Weld. World. 49 (2005) 69-75. doi:10.1007/BF03266478.

[5] Y.M. Hwang, Z.W. Kang, Y.C. Chiou, H.H. Hsu, Experimental study on temperature distributions within the workpiece during friction stir welding of aluminum alloys, Int. J. Mach. Tools Manuf. 48 (2008) 778-787 doi:10.1016/j.ijmachtools.2007.12.003.

[6] M. Imam, K. Biswas, V. Racherla, On use of weld zone temperatures for online monitoring of weld quality in friction stir welding of naturally aged aluminium alloys, Mater. Des. 52 (2013) 730-739. doi:10.1016/j.matdes.2013.06.014.

[7] S. Amini, M.R. Amiri, Pin axis effects on forces in friction stir welding process, Int. J.Adv. Manuf. Technol. 78 (2015) $1795-1801$. doi:10.1007/s00170-015-6785-z.

[8] R. Jain, S.K. Pal, S.B. Singh, Finite element simulation of pin shape influence on material flow, forces in friction stir welding, Int. J. Adv. Manuf. Technol. (2017) 1-17. doi:10.1007/s00170-017-0215-3.

[9] A. Forcellese, M. Martarelli, M. Simoncini, Effect of process parameters on vertical forces, and temperatures developed during friction stir welding of magnesium alloys, Int. J. Adv.Manuf. Technol. 85 (2016) 595-604. doi:10.1007/s00170-015-7957-6.

[10] R. Beygi, M. Kazeminezhad, M.Z. Mehrizi, G. Eisaabadi B, A. Loureiro, Friction stir butt welding of Al-Cu bilayer laminated composites: analysis of force, torque, and temperature, Int. J. Adv. Manuf. Technol. 88 (2017) 393-400. doi:10.1007/s00170-016- 8778.

[11] B. Das, S. Pal, S. Bag, Design and development of force and torque measurement setup for real time monitoring of friction stir welding process, Meas. J. Int. Meas. Confed. 103 (2017) 186-198. doi:10.1016/j.measurement.2017.02.034. 
[12] H.F. Wang, J.L. Wang, D.W. Zuo, W.W. Song, Application of Stir Tool Force Measuring Dynamometer for Friction Stir Welding of Aluminum Alloys, Strength Mater. 49 (2017) 162-170. doi:10.1007/s11223-017-9854-8.

[13] H. Su, C.S. Wu, A. Pittner, M. Rethmeier, Simultaneous measurement of tool torque, traverse force and axial force in friction stir welding, J. Manuf. Process. 15 (2013) 495- 500. doi:10.1016/j.jmapro.2013.09.001.

[14] B. Das, S. Pal, S. Bag, Torque based defect detection and weld quality modelling in friction stir welding process, J. Manuf. Process. 27 (2017) 8-17. doi:10.1016/j.jmapro.2017.03.012.

[15] U. Kumar, I. Yadav, S. Kumari, K. Kumari, N. Ranjan, R.K. Kesharwani, R. Jain, S. Kumar, S. Pal, D. Chakravarty, S.K. Pal, Defect identification in friction stir welding using discrete wavelet analysis, Adv. Eng. Softw. 85 (2015) 4350.doi:10.1016/j.advengsoft.2015.02.001.

[16] R. Ranjan, A.R. Khan, C. Parikh, R. Jain, R.P. Mahto, S. Pal, S.K. Pal, D. Chakravarty, Classification and identification of surface defects in friction stir welding: An image processing approach, J. Manuf. Process. 22 (2016) 237-253. doi:10.1016/j.jmapro.2016.03.009.

[17] P. Sinha, S. Muthukumaran, R. Sivakumar, S.K. Mukherjee, Condition monitoring of first mode of metal transfer in friction stir welding by image processing techniques, Int. J. Adv. Manuf. Technol. 36 (2008) 484-489. doi:10.1007/s00170-006-0854-2.

[18] R. Rajashekar, B.M. Rajaprakash, Development of a model for friction stir weld quality assessment using machine vision and acoustic emission techniques, J. Mater. Process. Technol. 229 (2016) 265-274. doi:10.1016/j.jmatprotec.2015.09.030.

[19] C. Chen, R. Kovacevic, D. Jandgric, Wavelet transform analysis of acoustic emission in monitoring friction stir welding of 6061 aluminum, Int. J. Mach. Tools Manuf. 43 (2003) 1383-1390. doi:10.1016/S0890-6955(03)00130-5.

[20] B. Das, S. Pal, S. Bag, Monitoring of Friction Stir Welding Process using Main Spindle Motor Current, J. Inst. Eng. Ser. C. (2017) 16. doi:10.1007/s40032-017-0371-0.

[21] D.T. Thekkuden, A. Santhakumari, A. Sumesh, A.-H.I. Mourad, K. Rameshkumar, Instant detection of porosity in gas metal arc welding by using probability density distribution and control chart, Int. J. Adv. Manuf. Technol. (2018). doi:10.1007/s00170-017-1484-6.

[22] H.J. Liu, H. Fujii, M. Maeda, K. Nogi, Tensile properties and fracture locations of friction-stir-welded joints of 6061-T6 aluminum alloy, J. Mater. Sci. Lett. 22 (2003) 1061-1063. doi:10.1016/S0924-0136(03)00806-9.

[23] G.M. Reddy, P. Mastanaiah, K.S. Prasad, T. Mohandas, Microstructure and mechanical property correlations in AA 6061 aluminium alloy friction stir welds, Trans. Indian Inst. Met. 62 (2009) 49-58. doi:10.1007/s12666-009-0007-Z.

[24] S. Rajakumar, C. Muralidharan, V. Balasubramanian, Statistical analysis to predict grain size and hardness of the weld nugget of frictionstir-welded AA6061-T6 aluminium alloy joints, Int. J. Adv. Manuf. Technol. 57 (2011) 151-165. doi:10.1007/s00170-011-3279-5.

[25] S. Rengarajan, V.S. Rao, Characteristics of AA7075-T6 and AA6061-T6 friction welded joints, Trans. Can. Soc. Mech. Eng. 39 (2015) $845-854$.

[26] J. Teimurnezhad, H. Pashazadeh, A. Masumi, Effect of shoulder plunge depth on the weld morphology, macrograph and microstructure of copper FSW joints, J. Manuf. Process. 22 (2016) 254-259. doi:10.1016/j.jmapro.2016.04.001.

[27] N.Z. Khan, A.N. Siddiquee, Z.A. Khan, S.K. Shihab, Investigations on tunneling and kissing bond defects in FSW joints for dissimilar aluminum alloys, J. Alloys Compd. 648 (2015) 360-367. doi:10.1016/j.jallcom.2015.06.246.

[28] W.M.S. Wan Sulong, M.A. Rojan, M.N. Mazlee, Influence of tool plunge depth on the joint strength and hardness of friction stir welded AA6061 and mild steel, Adv. Struct. Mater. 85 (2018) 373-383. doi:10.1007/978-3-319-72697-7 30

[29] N.Z. Khan, Z.A. Khan, A.N. Siddiquee, Effect of Shoulder Diameter to Pin Diameter (D/d) Ratio on Tensile Strength of Friction Stir Welded 6063 Aluminium Alloy, Mater. Today Proc. 2 (2015) 1450-1457. doi:10.1016/j.matpr.2015.07.068.

[30] S. Eslami, L. Mourão, N. Viriato, P.J. Tavares, P.M.G.P. Moreira, Multi-axis force measurements of polymer friction stir welding, J. Mater. Process. Technol. 256 (2018) 51-56. doi:10.1016/j.jmatprotec.2018.01.044.

[31] M. Mehta, K. Chatterjee, A. De, Monitoring torque and traverse force in friction stir welding from input electrical signatures of driving motors, Sci. Technol. Weld. Join. 18 (2013) 191-197.

[32] M.S. Węglowski, S. Dymek, Relationship between friction stir processing parameters and torque, temperature and the penetration depth of the tool, Arch. Civ. Mech. Eng. 13 (2013) 186-191.

[33] W.R. Longhurst, I.C. Wilbur, B.E. Osborne, B.W. Gaither, Process monitoring of friction stir welding via the frequency of the spindle motor current, Proc. Inst. Mech. Eng. Part B J. Eng. Manuf. 232 (2018) 720-730. doi:10.1177/0954405416654089.

[34] G. Swaminathan \& S. Sathiyamurthy, Experimental Study of Mechanical and Metallurgical Properties of Friction Stir Welded Dissimilar Aluminum Alloys, Int. J. Mech. Prod. Eng. Res. Dev. 8 (2018) 1049-1058.

[35] S.S. Kumar, S.D. Ashok, S. Narayanan, Investigation of friction stir butt welded aluminium alloy flat plates using spindle motor current monitoring method, Procedia Eng. 64 (2013) 915-925. doi:10.1016/j.proeng.2013.09.168.

[36] Ibrahim Sabry and Ahmed M. El-Kassas "Comparative Study on Different Tool Geometrics in Friction Stirred Aluminum Welds Using Response Surface Methodology" 4th International Conference on Welding and Failure Analysis of Engineering Materials (wafa-2018), November 19-22, 2018, Aswan, Egypt. 